\title{
Clinical Validity of the National Hearing Screening Method for Transitional Ages: A Proposal of Accurate Screening for Early Hearing Loss Detection
}

\author{
Hee Jun Yi, MD, Hyun Jung Kim, MD, and Michelle J. Suh, MD \\ Department of Otorhinolaryngology, Jeju National University College of Medicine, Jeju, Korea
}

\begin{abstract}
- ABSTRACT -
Objectives: The purpose of this study was to investigate whether the current $1,000-\mathrm{Hz}$ hearing screening test in transitional ages actually reflects the hearing status of Korean adults. Materials and Methods: Retrospective crosssectional analysis from the 2010-2012 Korean National Health and Nutrition Survey for adults aged 40 years or older. A questionnaire that could affect hearing and pure tone audiometry was conducted. Data were analyzed using complex samples general linear analyses and t-tests, and relative operating characteristic analysis. Hearing threshold averages by gender and age groups, and the appropriate screening frequency and cutoff values were calculated. Results: The overall prevalence of referred cases was 7.7\% [95\% confidence interval (CI), 7.3-8.2\%] according to the criterion standard. Hearing loss above $40 \mathrm{~dB}$ HL was observed in 10\%, but mild hearing loss was observed in $18.3 \%$. The 1,000-Hz screening test obtained a sensitivity of $67.5 \%(95 \% \mathrm{CI}, 66.5-73.5 \%)$ and a specificity of 98.9\% (95\% CI, 98.7-99.1\%). Among the cases screening as passing, 3.5\% had hearing loss above $40 \mathrm{~dB}, 0.9 \%$ had low-frequency hearing loss, and $24.9 \%$ had high-frequency hearing loss. In particular, the discrepancy between the high-frequency hearing loss and the screening results was greater in men. The ROC analysis showed the largest AUC at $2,000 \mathrm{~Hz}$ in all subjects. The average threshold of 1,000 and 3,000 Hz showed the best screening performance. Conclusions: The conventionally used $1,000-\mathrm{Hz}$ hearing surveillance method is limited in reflecting the actual hearing status of Korean adults. Therefore, a modification from single frequency to two frequencies combination of screening method to detect the early stages of hearing loss is needed. (J Clinical Otolaryngol 2020;31:37-44)
\end{abstract}

KEY WORDS: Korean National Health and Nutrition Examination Surveys · Hearing impairment • Screening test $\cdot$ Sensitivity $\cdot$ Specificity $\cdot$ Receiver operating characteristic.

\section{Introduction}

As the elderly population increases, the hearing-impaired population is also increasing, and many people are interested in hearing loss. In particular, by 2026 , Korea will have become a super-aged society in which the elderly population aged 65 years old and older comprises $20 \%$ of the total population due to rapid ag-

논문접수일: 2020년 4월 27일

논문수정일: 2020년 5월 12일

심사완료일: 2020년 5월 30일

교신저자: 서지영, 63241 제주특별자치도 제주시 아란13길 15

제주대학교 의과대학 이비인후과학교실

전화 : (064) 717-8173·전송: (064) 717-1131

E-mail: myzetapotential@gmail.com ing, according to the government statistical service in 2011. ${ }^{1)}$ Accordingly, national interest in aging well is increasing. Recent studies have shown that deafness increases and worsens dementia as well as cognitive impairment. ${ }^{2)}$ There is also a link between hearing loss and depression. ${ }^{3)}$

Since these issues give rise to social problems, it is necessary to diagnose hearing loss more quickly and find a solution, thus reflecting the importance of screening tests for early detection and intervention. As part of this effort, the Department of Health and Welfare in Korea has been conducting a 'Screening Program for Transitional Ages' lifespan health checkup since 2007 for groups of adults aged 40 years and 66 years (defining those as transitional ages), providing a systematic follow- 
up of high-risk groups and disease groups (Ministry of Health and Welfare. Notification No. 2007-126 of the National Screening Program for the transitional Ages in Korea. 2007). In this program, a hearing screening surveillance test is conducted by deciding to 'refer or pass' at $1,000 \mathrm{~Hz}$ pure tone audiometry (Considering expense and time, formal audiometric testing is not available). Recently, there has been an effort to adjust the screening items by generation and gender, but the evidence is insufficient. For hearing, there is the problem of insufficient evidence on examination items, and the validity of the screening test must be verified. ${ }^{4-6)}$ However, to date, there has been no validation of hearing screening results in large population studies in Korea; thus, one can only borrow foreign recommendations or collect expert opinions.

The purpose of this study is to investigate how well the conventionally used standard screening method can detect hearing loss early, reflect the auditory characteristics of Korean adults and consider the matter to be supplemented. The results of this study provide useful information to clinicians regarding the evaluation and management of hearing loss and the education of patients in primary settings.

\section{Materials and Methods}

\section{Enrolled subjects}

The Korean National Health and Nutrition Survey (KNHNS) was conducted by the Centers for Disease Control Headquarters of Korea to obtain nationwide statistics for the assessment of the health and nutritional status of Koreans. This study was based on data from the survey for 3 years (2010-2012), with the sampling performed through a stratified cluster extraction method for the whole population of Korea. The original study complied with the Declaration of Helsinki and was approved by the appropriate ethics review board. All participants provided informed consent. The present study was exempted from ethics review by virtue of it being a secondary study.

The KNHNS was conducted on subjects aged 40 years or older who underwent pure tone audiometry.
Of the 11,675 subjects over the age of 40, 11,037 participants who completed the hearing test and questionnaire were analyzed, except those in whom chronic otitis media $(\mathrm{n}=638)$. Chronic otitis media was diagnosed by trained otolaryngologists based on responses to a questionnaire and otoendoscopic findings. In addition to hearing evaluation, the presence of hearing difficulty, tinnitus, and history of noise exposure were determined based on subjects' response (s) to a question/questionnaire (Appendix Table 1). Of the selected 11,037 subjects, $48.2 \%$ were men and $51.8 \%$ were women. The mean age of the subjects was $58.3 \pm 11.6$ years (mean $\pm \mathrm{SD}$ ). The age groups were classified into 10-year intervals: $40-49,50-59,60-69$, and 70 years or older.

\section{Evaluation of hearing threshold}

The air-conduction hearing threshold was evaluated by trained otolaryngologists using an automatic audiometer (GSI SA-203; Entomed Diagnostics AB, Lena Nodin, Sweden) in a soundproof booth. The current "national screening pass criterion" which is defined as a pure-tone threshold less than or equal to $40 \mathrm{~dB} \mathrm{HL}$ (hearing level) at $1,000 \mathrm{~Hz}$ is used. Passing or failing (refer) results of $1,000-\mathrm{Hz}$ screening pure-tone audiometry and conventional pure-tone audiometric results were compared at various frequencies $(500,1,000$, $2,000,3,000,4,000$, and $6,000 \mathrm{~Hz}$ ). The results of conventional pure-tone test were considered to be the "gold standard." To confirm the consistency of the test results, the measured thresholds were re-examined at 1 $\mathrm{kHz}$, and hearing tests were reperformed when the difference was $5 \mathrm{~dB}$ or more.

The cutoff point for determining hearing loss was a pure-tone average of $40 \mathrm{~dB}$ for the frequencies. Hearing loss (unilateral or bilateral) was considered to be present if the mean value of the air-conduction thresholds for 500-, 1,000-, 2,000-, and 4,000-Hz pure-tone sounds was greater than $40 \mathrm{~dB}$ in at least one ear (which was adapted from WHO (World Health Organization)-proposed better-ear 4fPTA method). ${ }^{7,8)}$ 


\section{Statistical analysis}

Primary data were used from the Korean Centers for Disease Control and Prevention. A complex sample plan file was designed to apply $\mathrm{k}$ strata, primary sample units, and proper usage of sampling weight values. The factors related to hearing loss were analyzed using PASW $^{\circledR}$ Statistics 18 (IBM Corp., Armonk, NY, USA). Values in this study are categorical variables, expressed as percentages (weighted). The comparison of hearing values between groups was analyzed using complex sample general linear analyses. Using audiometry as a reference test, the sensitivity, specificity and most appropriate screening frequency were detected by receiver operator characteristic (ROC) analysis.

\section{Results}

\section{Clinical characteristics of the subjects}

Table 1 shows the characteristics of the subjects' gender and age, hearing discomfort, tinnitus, and noise exposure. Most of the subjects were in their 40s and $50 \mathrm{~s}$ ( $37.9 \%$ and $30.5 \%$, respectively). Fifteen percent of subjects complained of subjective hearing discomfort. In fact, when complaining of subjective discomfort, mild HL (25-40 dBHL in 4fPTA) occupied the largest ratio at $31.8 \%$ than moderate $(21.8 \%, 40-$ $60 \mathrm{dBHL})$, and above hearing loss $(4.5 \%, 60 \mathrm{dBHL}$ and over).

Compared to the rate of subjective hearing discomfort, the rate of referred cases in the actual screening test was small (The prevalence of those referred for at least one ear was $11.2 \%$ ) (Table 1). Even with a screen pass results, mild HL reached $14.7 \%$ and moderate hearing loss with $1.9 \%$.

For accurate analysis, the inclusion of both ears shows a failure (referred) rate of $7.7 \%$ on the screening test. Furthermore, according to the degree of hearing loss, the prevalence of those above the threshold of moderate (40 dB and more) HL was $10.0 \%$, and those with mild hearing impairment accounted for $18.3 \%$ of the total. Putting this together, through the gap between hearing discomfort and referral results, we could find a justification to examine whether mild HL was being overlooked.

\section{Discrepancy between screening and actual hearing threshold by age and gender}

We further focused on discrepancies between the results of the $1-\mathrm{kHz}$ screening test and the conventional audiometry test. First, the average hearing thresholds

Table 1. General characteristics of the study participants

\begin{tabular}{lcc}
\hline \multirow{2}{*}{ Characteristics } & \multicolumn{2}{c}{ Number of subjects (1 1,037 subjects) } \\
\cline { 2 - 3 } $\begin{array}{l}\text { Gender } \\
\text { Women }\end{array}$ & $\mathrm{n}$ & $\%(95 \% \mathrm{Cl})$ \\
$\quad$ Men & 6,294 & $51.8(51.2-52.9)$ \\
Age & 4,743 & $48.2(47.1-48.8)$ \\
$40 \leq,<50$ & & \\
$50 \leq,<60$ & 2,983 & $37.9(36.3-39.6)$ \\
$60 \leq,<70$ & 3,097 & $30.5(29.2-31.9)$ \\
$70 \leq$ & 2,623 & $17.1(16.3-18.0)$ \\
Complaint of hearing loss & $14.4(13.6-15.3)$ \\
$(+)$ & 2,334 & \\
$(-)$ & 1,983 & $15(14.2-16.0)$ \\
& 9,050 & $85(84-85.8)$
\end{tabular}

Referred subjects (at least one ear)
$(+)$
1,426
$11.2(10.4-12.0)$

$(-)$

8,821

$88.8(88.0-89.6)$

Tinnitus

$(+)$

2,609

$22.2(21.1-23.3)$

$(-)$

8,395

$77.8(76.7-78.9)$

Noise exposure history

$\begin{array}{lll}(+) & 3,257 & 33.1(31.1-35.0)\end{array}$

$\begin{array}{lll}(-) & 7.794 & 66.9(65.0-68.9)\end{array}$

Number of tested ears (22,074 subjects)

\begin{tabular}{lrc}
\hline $\begin{array}{l}\text { Screening pass/ refer } \\
\text { Refer }\end{array}$ & 1,998 & $7.7(7.3-8.2)$ \\
Pass & 18,496 & $92.3(91.8-92.7)$ \\
Degree of hearing loss $(\mathrm{dB} \mathrm{HL})$ & \\
$\leq 25$ & 13,595 & $71.7(70.9-72.5)$ \\
$25 \leq,<40$ & 4,332 & $18.3(17.6-18.9)$ \\
$40 \leq,<60$ & 1,862 & $7.3(6.9-7.8)$ \\
$60 \leq,<80$ & 443 & $1.6(1.4-1.8)$ \\
$80 \leq$ & 261 & $1.1(0.9-1.3)$ \\
\hline$\%$
\end{tabular}

$\%$ : weighted percentage 
Table 2. Audiometric thresholds ( $\mathrm{dB} \mathrm{HL}$ ) of overall and each frequency in the passing and referred hearing groups $(n=22,074$ ears $)$

\begin{tabular}{lccccccc}
\hline \multicolumn{1}{c}{ Frequency $(\mathrm{kHz})$} & $0.5-1-2-4^{*}$ & 0.5 & 1 & 2 & 3 & 4 & 6 \\
\hline $\begin{array}{l}\text { Overall } \\
\text { Pass }\end{array}$ & $18.3 \pm 10.7$ & $18.8 \pm 16.0$ & $16.8 \pm 16.8$ & $20.9 \pm 18.7$ & $26.8 \pm 22.0$ & $31.8 \pm 23.9$ & $43.5 \pm 25.3$ \\
$\quad$ Refer & $57.4 \pm 18.6$ & $51.0 \pm 22.8$ & $55.9 \pm 18.6$ & $57.1 \pm 21.4$ & $62.7 \pm 22.2$ & $65.7 \pm 22.6$ & $78.7 \pm 21.4$ \\
Men & & & & & & & \\
$\quad$ Pass & $20.6 \pm 11.3$ & $14.8 \pm 10.1$ & $12.3 \pm 9.5$ & $18.1 \pm 14.9$ & $28.0 \pm 20.0$ & $37.1 \pm 22.9$ & $45.5 \pm 24.7$ \\
$\quad$ Refer & $59.2 \pm 17.8$ & $49.1 \pm 21.6$ & $54.8 \pm 17.3$ & $60.6 \pm 20.2$ & $69.3 \pm 20.2$ & $73.5 \pm 20.3$ & $83.3 \pm 19.1$ \\
Women & & & & & & & \\
$\quad$ Pass & $16.5 \pm 9.9$ & $15.8 \pm 10.2$ & $12.7 \pm 9.7$ & $16.2 \pm 12.2$ & $19.0 \pm 14.5$ & $21.3 \pm 16.2$ & $35.3 \pm 19.9$ \\
$\quad$ Refer & $56.1 \pm 19.1$ & $52.5 \pm 22.5$ & $56.2 \pm 19.0$ & $55.2 \pm 21.7$ & $58.6 \pm 22.3$ & $60.5 \pm 22.6$ & $76.5 \pm 21.9$ \\
\hline
\end{tabular}

*: Mean hearing loss of more than $40 \mathrm{~dB}$ using a method of calculating the mean of 4 frequencies [calculated by $(a+b+c+d) / 4$, where $500(a), 1000(b), 2,000(c), 4,000(d) H z]$

Table 3. Comparison of the 1,000-Hz screening test (health checkup test) and conventional audiometry

\begin{tabular}{|c|c|c|c|c|c|c|}
\hline \multirow{2}{*}{$\begin{array}{c}\text { Health } \\
\text { checkup } \\
\text { test* }\end{array}$} & \multicolumn{2}{|c|}{$\begin{array}{l}\text { Pure tone audiometry } \\
(0.5-1-2-4 \mathrm{kHz})^{\dagger}\end{array}$} & \multicolumn{2}{|c|}{$\begin{array}{c}\text { Low-frequency } \\
\text { average }^{\dagger}\end{array}$} & \multicolumn{2}{|c|}{$\begin{array}{l}\text { High-frequency } \\
\text { average }\end{array}$} \\
\hline & $\mathrm{NH}$ & $\mathrm{HI}$ & $\mathrm{NH}$ & $\mathrm{HI}$ & $\mathrm{NH}$ & $\mathrm{HI}$ \\
\hline \multicolumn{7}{|l|}{ Overall } \\
\hline Refer & $12.6(10.9-14.5)$ & $87.4(85.5-89.1)$ & $18.6(16.6-20.9)$ & $81.4(79.1-83.4)$ & $8.2(6.8-9.8)$ & $91.8(90.2-93.2)$ \\
\hline Pass & $96.5(96.1-96.8)$ & $3.5(3.2-3.9)$ & 99.1 (98.9-99.2) & $0.9(0.8-1.1)$ & $75.1(74.3-75.9)$ & $24.9(24.1-25.7)$ \\
\hline \multicolumn{7}{|l|}{ Men } \\
\hline Refer & $8.3(6.2-10.9)$ & $91.7(89.1-93.8)$ & $18.4(15.4-21.9)$ & $81.6(78.1-84.6)$ & $3.6(2.4-5.5)$ & $96.4(94.5-97.6)$ \\
\hline Pass & $94.8(94.2-95.4)$ & $5.2(4.6-5.8)$ & 99.0 (98.7-99.2) & $1.0(0.8-1.3)$ & $65.0(63.7-66.3)$ & $35.0(33.7-36.3)$ \\
\hline \multicolumn{7}{|l|}{ Women } \\
\hline Refer & $16.0(13.5-18.8)$ & $84.0(81.2-86.5)$ & $18.8(16.2-21.7)$ & $81.2(78.3-83.8)$ & $11.8(9.5-14.5)$ & $88.2(85.5-90.5)$ \\
\hline Pass & $98.0(97.7-98.3)$ & $2.0(1.7-2.3)$ & 99.1 (98.9-99.3) & $0.9(0.7-1.1)$ & $84.8(83.9-85.6)$ & $15.2(14.4-16.1)$ \\
\hline
\end{tabular}

*: 1,000-Hz screening test; fail (hearing impairment) was defined as a level above $40 \mathrm{~dB} \mathrm{HL}, \dagger:$ Mean hearing loss of more than $40 \mathrm{~dB}$ using a method of calculating the mean of 4 frequencies [calculated by $(a+b+c+d) / 4, w h e r e$ 500 (a) , 1,000 (b), 2,000 (c), 4,000 (d)], ‡: low frequency: 0.5-1-2 Hz, §: high frequency: 3-4-6 kHz. NH: normal hearing, HI: hearing impaired

passed and referred were $18.3 \pm 10.7$ (means \pm SD) and $57.4 \pm 18.6 \mathrm{~dB} H L$, respectively (Table 2 ). In the overall sample and among the males, at $6,000 \mathrm{~Hz}$, both the passing and referred groups had more than $40 \mathrm{~dB}$ of hearing loss. We examined the relationship between the screening results and hearing by frequency (Table 3). Overall, $3.5 \%$ of the passed cases $(5.2 \%$ and $2.0 \%$ of passed males and females, respectively) had more than moderate hearing loss. Furthermore, we examined the relationship between the results of screening and the mean threshold of overall, low and high frequencies (we divided study frequency into low $(0.5-1-2 \mathrm{kHz})$ and high frequency (3-4-6 kHz area), respectively. Inter- estingly, high-frequency hearing loss is present in $24.9 \%$ of subjects who passed the screening - $35 \%$ in men who passed and $15.2 \%$ in women who passed. In other words, screening at $1,000 \mathrm{~Hz}$ alone showed that screening has limitations in reflecting hearing loss, especially hearing loss at high frequencies.

Receiver operating characteristic (ROC) analysis: Diagnostic accuracy of the $1,000-\mathrm{Hz}$ screening method and the suggestion of an appropriate screening test

As we draw the ROC curve for each frequency with an average $40 \mathrm{~dB}$ of $0.5,1,2$, and $4 \mathrm{~Hz}$ as the gold standard, we can see that $2,000 \mathrm{~Hz}$ shows the largest Area Under the Curve (AUC) in all subjects (At the 
same time, the cutoff value is $37.5 \mathrm{~dB}$ HL)(Table 4). Furthermore, ROC analysis was performed by combining the frequencies with the highest AUC, and a higher AUC score was obtained when the average $1,000,3,000 \mathrm{~Hz}$ threshold was used. In a further analysis by age and gender, men showed the same result in the same manner (AUC at 2,000 Hz and higher at the 1,000, 3,000 Hz screening). Women showed the highest AUC at $1,000 \mathrm{~Hz}$ and the highest AUC in the $1,000,3,000 \mathrm{~Hz}$ combination. In the age-specific analysis, all age groups obtained the highest AUC score at combination of $1,000-3,000 \mathrm{~Hz}$ (data not shown).

\section{Discussion}

The purpose of screening tests is to detect disease and further study it before it progresses.

It is a substrategy rather than primary prevention, but its effect and importance are increasing with the development of medical technology. Age-related hearing loss and presbycusis are inevitable and difficult to recognize early and are often recognized after hearing loss actually occurs. According to our hearing results among adults over 40 years of age, those with mild HL ( $25 \mathrm{~dB}$ HL and more) comprised the largest proportion (Table 1) of the hearing-impaired subjects rather than cases with further progression. This suggests that the characteristics of the early stage of hearing loss should be adequately observed at the screening stage.

In fact, as mentioned earlier, passed cases had considerable proportion of mild HL. When calculating 25 $\mathrm{db} \mathrm{HL}$ as the criterion for judgment, the refer rate reaches $22.9 \%$ higher than the previous one, and the sensitivity increases but the specificity decreases (68.2, $93.1 \%$, respectively) compared to the case of setting 40 $\mathrm{dB} H \mathrm{HL}$ as the screening criterion.

As a screening tool, considering the need for cost effectiveness, it is not appropriate Actually, the highest AUC was obtained when the cut off value was 27.5 at $1,000 \mathrm{~Hz}$ (Table 2). Even, 1,000 Hz screening also showed a significant discrepancy between the high-frequency hearing level and the $1,000-\mathrm{Hz}$ screening re-

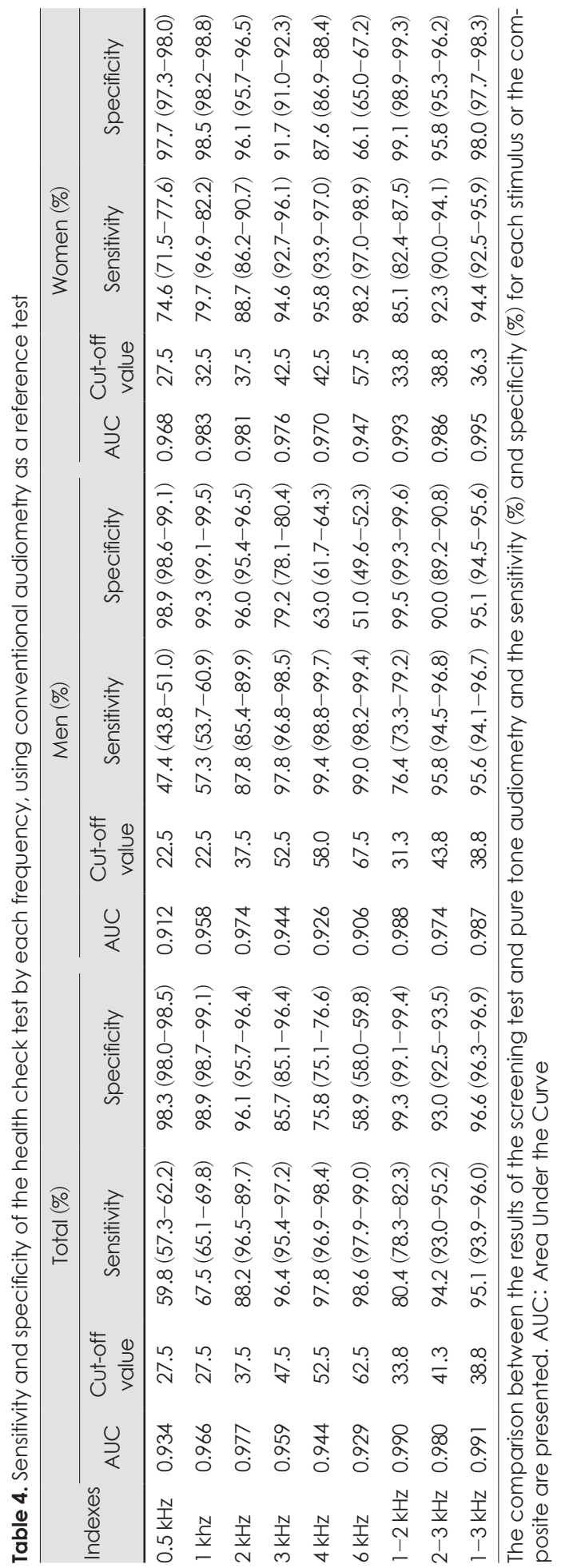


sult. That is, a single-frequency $1,000-\mathrm{Hz}$ test is not sufficient to identify the risk group of hearing loss through screening because hearing loss starts from high frequencies. Even among cases that passed the screening process, hearing loss at high frequencies accounted for $24.9 \%$ of the total, of which $35 \%$ was higher for men than women $(15.2 \%)$.

Why have we used $1,000 \mathrm{~Hz}$ for screening thus far? This frequency is representative of the major speech bands. In other words, frequencies across $0.5-4 \mathrm{kHz}$ contain consonants and vowels that are critical for understanding speech, and $1 \mathrm{kHz}$ is located in the middle of the conversational range, a large part of which is listening to the language. Therefore, this frequency can be easily used in screening.

Previous studies in the past conducted in other countries regarding the question of frequency, but the number was small, and the findings were not implemented in Korea. These studies have suggested inconsistently in which 2,000 $\mathrm{Hz}$ or combination of 1,000 and 2,000 $\mathrm{Hz}$ as best screening method. ${ }^{9-11)}$ Even they confined to older ages over 60 . Meanwhile, our study showed that $2,000 \mathrm{~Hz}$ was ideal for a single-frequency method, and even higher ROC results were obtained when two frequencies were combined, indicating that the most appropriate method was a combination of 1,000 and 3,000 Hz. Even the combination of 1,000-3,000 Hz repeatedly showed the highest AUC in each age group analysis.

This is mainly due to the early deterioration that occurs in the high-frequency region; with a lack of use, it begins to develop relatively early, even in an individual's 30 s, and gradually progresses to middle and low frequencies. $^{12,13)}$

Additionally, the discrepancy between screening and frequency-dependent hearing results was higher for men than for women in the high-frequency range. This was in line with the findings of a previous study noting that hearing loss occurs earlier in men than in women and was greater in magnitude in men than in women for frequencies between 2 and $12 \mathrm{kHz}$ but not $\leq 1 \mathrm{kHz}$ and $>12 \mathrm{kHz}$ due to genetic and environmental (multi- factorial) reasons. ${ }^{14,15)}$ In South Korea, the occurrence of noise-induced hearing loss is significant, as most adult men have experience in military duty in their $20 \mathrm{~s}$ and 30s. ${ }^{16)}$ Therefore, the AUC was calculated assuming that the most appropriate single-frequency screening for men and women was different. However, hearing differences by gender did not lead to differences in best screening analysis. As the combination of 1,000, $3,000 \mathrm{~Hz}$ showed the largest AUC in both men and women.

This study is meaningful, as it is the first to conduct the validity of a hearing screening test for adults representing Koreans cross-sectionally. Health screenings are part of secondary prevention and premature detection before disease progression. ${ }^{17)}$ In the early discovery of hearing loss, we should see that the onset of hearing loss occurs from high frequencies. ${ }^{18)}$ This study also clinically suggested that high-frequency hearing loss $(3,000 \mathrm{~Hz})$ as well as hearing loss at $1,000 \mathrm{~Hz}$ should be considered. There were more cases of subjective discomfort of hearing than referral with at least one ear. Even in adults who passed, more subjects who felt discomfort in subjective hearing showed high-frequency hearing loss than did those who did not experience hearing discomfort.

According to previous studies, people with high-frequency hearing loss may have trouble understanding normal speech because they can have problems hearing consonant letters that contribute to the clarity of speech and experiencing difficulties hearing conversations in larger groups in noisy places or in places with background noise. ${ }^{19)}$ Furthermore, those with high-frequency hearing loss in the presence of normal speech frequency hearing had higher ORs of having anxiety and stress compared to those with normal hearing across speech and high frequencies. ${ }^{20)}$ These are not only highfrequency hearing loss (which was worse than those who did not feel discomfort in passed subjects), although mild loss below $25 \mathrm{~dB}$ HL. To date, the association between $\mathrm{HL}$ and cognitive deterioration began to occur even with less than $25 \mathrm{~dB} \mathrm{HL}$, the threshold of known mild hearing loss. 
Although this study did not examine hearing and cognition, this relationship should not be overlooked.

In the analysis of the group that was screened as passing, the average hearing level of symptomatic hearing impaired subjects was worse than in those without symptoms (24.9 dB HL vs. 16.0), which shows that our current cutoff level ( $40 \mathrm{~dB}$ HL) is fairly high and limited to describing symptomatic hearing loss. We suggest that stricter screening is necessary.

Considering recent findings of the relationship between hearing loss and cognitive deterioration, we conclude that the current single frequency of $1,000 \mathrm{~Hz}$ screening (in current referral process) is insufficient to describe early deterioration of high frequency hearing loss and mild hearing loss, so it needs to be discovered with both the 1,000- and 3,000-Hz tests in Korean adults.

\section{REFERENCES}

1) Moon H, Kim D, Yoon H, Park C, Lee S, Lee S. Socioeconomic impacts of population aging and policy issues. Seoul: Korea Development Institute 2006:36.

2) Loughrey DG, Kelly ME, Kelley GA, Brennan S, Lawlor BA. Association of age-related hearing loss with cognitive function, cognitive impairment, and dementia: a systematic review and meta-analysis. JAMA Otolaryngol Head Neck Surg 2018;144:115-26.

3) Hsu WT, Hsu CC, Wen MH, Lin HC, Tsai HT, Su P, et al. Increased risk of depression in patients with acquired sensory hearing loss: a 12-year follow-up study. Medicine 2016; 95(44):e5312.

4) Ito K, Naito R, Murofushi T, Iguchi R. Questionnaire and interview in screening for hearing impairment in adults. Acta Otolaryngol Suppl 2007;127:24-8.

5) Martin K, Church G. Prevalence of hearing impairment among university students. J Am Acad Audiol 1991;2(1): $32-5$.

6) Wang YF, Wang SS, Tai CC, Lin LC, Shiao AS. Hearing screening with portable screening pure-tone audiometer and distortion-product otoacoustic emissions. Zhonghua Yi
Xue Za Zhi (Taipei) 2002;65(6):285-92.

7) Stevens G, Flaxman S, Brunskill E, Mascarenhas M, Mathers CD, Finucane M. Global and regional hearing impairment prevalence: an analysis of 42 studies in 29 countries. Eur J Public Health 2013;23(1):146-52.

8) W.H. Organization, Deafness and Hearing Loss. http:// www. who. int/mediacentre/factsheets/fs300/en (2018).

9) Ciurlia-Guy E, Cashman M, Lewsen B. Identifying hearing loss and hearing handicap among chronic care elderly people. Gerontologist 1993;33(5):644-49.

10) Lichtenstein MJ, Bess FH, Logan SA. Validation of screening tools for identifying hearing-impaired elderly in primary care. JAMA 1988;259(19):2875-8.

11) McBride WS, Mulrow CD, Aguilar C, Tuley MR. Methods for screening for hearing loss in older adults. Am J Med Sci 1994;307(1):40-2.

12) Robinson D, Sutton G. Age effect in hearing-a comparative analysis of published threshold data. Audiology 1979;18(4): 320-34.

13) Jerger J, Chmiel R, Stach B, Spretnjak M. Gender affects audiometric shape in presbyacusis. J Am Acad Audiol 1993;4(1):42-9.

14) Kim S, Lim EJ, Kim HS, Park JH, Jarng SS, Lee SH. Sex differences in a cross sectional study of age-related hearing loss in Korean. Clin Exp Otorhinolaryngol 2010;3(1):27-31.

15) Lee FS, Matthews LJ, Dubno JR, Mills JH. Longitudinal study of pure-tone thresholds in older persons. Ear Hear 2005;26(1):1-11.

16) Kim S, Lim EJ, Kim TH, Park JH. Long-term effect of noise exposure during military service in South Korea. Int J Audiol 2017;56(2):130-6.

17) Leavell HR, Clark EG. Preventive Medicine for the Doctor in his Community. An Epidemiologic Approach. Preventive Medicine for the Doctor in his Community An Epidemiologic Approach;1958.

18) Fetoni AR, Picciotti PM, Paludetti G, Troiani D. Pathogenesis of presbycusis in animal models: a review. Exp Gerontol 2011;46(6):413-25.

19) Cho YS. Role of hearing aids in age-related hearing loss. J Clinical Otolaryngol 2014;25:14-9.

20) Jayakody DM, Almeida OP, Speelman CP, Bennett R, Moyle TC, Yiannos JM, et al. Association between speech and high-frequency hearing loss and depression, anxiety and stress in older adults. Maturitas 2018;110:86-91. 
J Clinical Otolaryngol 2020;31:37-44

\section{Appendix 1}

Appendix 1. Hearing related questionnaires

Hearing difficulty

Choose the sentence that best describes your hearing

1. I feel difficulty in hearing

2. I do not feel any difficulty in hearing

tinnitus

Have you ever heard a sound in your ear within the past year?

1. Yes

2. No

3. I cannot remember

Noise exposure

1. Have you worked for more than 3 months in a place with noise (such as mechanical or generator induced noise)?

1. Yes (at least one)

. Have you been exposed to loud noises for more than 5 hours

2. No

a week other than occupational exposures?

3. I cannot remember

3. So far, have you been exposed to sudden loud noises such as gunshots or explosions? 